\title{
EL ÚLTIMO MATRIMONIO FELIZ: UNA REPRESENTACIÓN PECULIAR DE LA MUJER EN EL GÉNERO TELENOVELA
}

\author{
THE LAST HAPPY MARRIAGE: A PECULIAR REPRESENTATION \\ OF WOMEN IN SOAP OPERAS
}

Mayra Rosario Yaranga Hernández ${ }^{1}$

\section{RESUMEN}

En los últimos años, a pesar de los grandes avances en el acceso a la información y a la educación, la representación de la mujer en los medios de comunicación parece en muchos casos haberse quedado estancada en la figura estereotipada de antaño. Un ejemplo particular de tal estancamiento se refleja en las telenovelas, que constituyen un elemento importante para la construcción de la identidad de la mujer, pero tienden a proponer imágenes fácilmente discernibles entre un binomio "buena/mala", sin considerar los matices complejos de la persona. Sin embargo, existen ejemplos que muestran un intento de ir más allá de dichos esquemas. Uno de ellos es la telenovela colombiana El último matrimonio feliz, que parte de una realidad social (la disolución de cada vez más matrimonios) para mostrar una imagen más realista de la mujer que debe pasar por dicho trance.

\section{Palabras clave}

Estereotipos, medios, identidad, telenovelas Latinoamericanas

\section{ABSTRACT}

In the last few years, despite major breakthroughs in the access to information and education, the representation of women in the media seems to have remained in a stereotyped image of old. A particular example of this appears in telenovelas, which constitute a crucial element in the formation of women's identity, but tend to suggest images ranging in an easily identifiable "good/ evil" binomial, without regard for a person's complex nuances. However, there are examples showing an attempt to move beyond such frames. One of them is the Colombian telenovela El último matrimonio feliz (The last happy marriage), starting from a social fact (the increasing number of failing marriages) to portray, in a more realistic way, women who have to overcome such a situation.

\section{Keywords}

Stereotypes, media, identity, Latinamerican soap operas

\section{LA REPRESENTACIÓN DE LA MUJER: UNA APROXIMACIÓN}

La representación de los grupos sociales, sean estos de género, edad, grupo étnico o grupo social, apunta tanto a caracterizar a dichos grupos como a asignarles implícitamente un rol dentro de la sociedad. Los medios de comunicación, tanto por medio de sus emisiones como por la publicidad que muestran, son responsables de la creación de una imagen colectiva que bien puede

Master of Arts en Medios, Cultura e Identidad otorgada en el Reino Unido por la Universidad de Roehampton. Catedrática en la UNIFÉ. 
reflejar acertadamente su realidad o bien distorsionarla mediante la generación y el refuerzo de estereotipos.

Con el paso del tiempo, el caso de la mujer ha cobrado especial importancia. Actualmente vivimos en una sociedad cada vez más consciente sobre el rol de la mujer en la estructura social y que condena el "regreso al pasado" en lo concerniente a las relaciones entre los géneros y en las actividades cotidianas de la vida de la mujer. Además, los medios de comunicación nos informan día tras día sobre casos de mujeres cuya integridad física o moral haya sido vulnerada, con el consiguiente llamado a la acción tanto para las autoridades como para la colectividad. Con la proliferación reciente de las redes sociales, este tipo de llamados se ha vuelto muy común gracias a la aparición de colectivos formales e informales que apoyan la igualdad de género y la defensa de la mujer ante cualquier abuso.

No obstante, el plano de la representación en los medios de comunicación cuenta una historia diferente. Por un lado, la publicidad actual tiende a mostrar a la mujer como un ser de cuerpo perfecto y de ambiciones consumistas, cuyo intelecto pasa invariablemente a segundo plano; si no es de esta forma, muestra a la mujer dentro de un contexto muy conocido: las tareas del hogar. Por otro lado, la imagen que los programas de televisión crean sobre la mujer dista mucho de ser precisa, en muchas ocasiones basándose en gastados estereotipos. El peligro de este tipo de representación no consiste en que sea incorrecta en sí misma, sino que al ser proyectada hacia la sociedad, su efecto resulta multiplicarse ya que quienes observan, por ejemplo, la publicidad o los programas televisivos no necesariamente poseen la capacidad de discernir lo normal de lo presentado. Como consecuencia, la imagen de la mujer que se genera no va necesariamente a gozar de los matices únicos que la caracterizan, sino que va a estar alimentada por muchas ideas y estereotipos que, lamentablemente, podrían equiparar la fuerza de las acciones descritas en el párrafo anterior.

Diversos sectores de la sociedad han tomado consciencia al respecto, $y$ han propuesto acciones o posibles soluciones al problema $\mathrm{de}$ representación. Un ejemplo puntual y que considero importante es Miss Representation, que inicialmente fue un documental dirigido por Jennifer Siebel (2011), cuyo lema es "You can't be what you can't see" ("No puedes ser lo que no puedes ver"). El documental tenía como objetivo demostrar que los medios de comunicación no han proporcionado a las mujeres jóvenes muchos ejemplos o modelos de éxito en el mundo actual, con lo que se da a entender que se necesita un cambio en la manera como los medios representan a la mujer y construyen sus aspiraciones. A partir de este trabajo se ha intentado tomar acción al involucrar al público, por ejemplo mediante el uso de Twitter para denunciar a los medios que muestren ideas ofensivas, la creación de guías informativas, entre otros.

Un punto que no debe escapar a nuestra atención es el de la participación femenina en los mismos medios de comunicación, sobre todo en los grupos que son responsables de la creación de contenidos o son parte integral de ellos. De acuerdo al informe del Proyecto de Monitoreo Global de Medios (GMMP) en el 2010 , el $24 \%$ de las personas que figuran en las noticias fueron mujeres. El mismo documento informó que de 84 páginas web relacionadas a noticias, el $23 \%$ era realizado por mujeres. Asimismo, en la industria del cine, el Centro para los Estudios de la Mujer en la Televisión y el Cine - Center for the Study of Women in Television and Film, presentó que el porcentaje de personas que trabajaron en la industria del cine en el 2012, detrás de las cámaras como directores, escritores, productores, editores y cinematógrafos alcanza un $18 \%$ de la participación de las mujeres. La misma institución presentó que en la industria de la televisión, el $26 \%$ de personas que trabajan detrás de las pantallas (directoras, editoras, entre otras) son mujeres. De estas cifras se puede colegir que tal vez la representación de un grupo, en este caso de las mujeres, también depende de la participación que dicho grupo tenga en la generación de contenidos de los medios. Si tomamos en cuenta cifras como las arriba mencionadas, tal vez esto nos lleve a pensar que la apabullante presencia masculina tiene alguna relación con el poco avance en la representación femenina dentro de los medios. 


\section{LA TELENOVELA COMO ESPACIO DE REPRESENTACIÓN}

La telenovela latinoamericana ha sido durante mucho tiempo un indicador del "espíritu de los tiempos" y su importancia no debe ser subestimada. Esto podría ser muy bien resumido por Martín Barbero:

Ningún otro género, ni el de terror $-y$ no es que falten motivos- ni el de aventuras $-y$ no es que no haya grandes selvas y ríos- ha logrado cuajar en la región como el melodrama. (...) sigue constituyendo un terreno precioso para estudiar la no contemporaneidad y los mestizajes de que estamos hechos. Porque como en las plazas de mercado, en el melodrama está todo revuelto, las estructuras sociales con las del sentimiento, mucho de lo que somos -machistas, fatalistas, supersticiosos- $y$ de lo que soñamos ser, el robo de la identidad, la nostalgia y la rabia. (Barbero 1987: 243)

Siguiendo esta idea, podemos afirmar que la ficción televisiva constituye un factor externo que contribuye a la construcción de la identidad. En este proceso, el primer paso será identificar el contexto (lugar, tiempo, personajes), para luego cotejar dicha representación con lo que se entiende por realidad. De esta manera, los grupos sociales van identificándose dentro del imaginario creado y también identifican al "otro".

Evidentemente, la realidad mostrada por las telenovelas difiere según el país de origen o de adaptación. Los países por excelencia en cuanto a telenovelas siempre han sido México, Brasil y recientemente Colombia. A continuación, veremos cómo la representación de un mismo tema varía en esos países.

Por un lado, las novelas mexicanas se han caracterizado por ser extremistas, mostrando grandes sufrimientos y amores imposibles. El amor solo se alcanza a través del sufrimiento y de la lucha "contra la corriente". Sin embargo, como lo propone Mazziotti (2008), a nivel dramatúrgico son envidiables pues los secretos no son descubiertos sino hasta el final, los malos pagan su condena y el relato se desarticula. En cuanto a la representación de la mujer, siempre existen dos extremos; por ejemplo, en la trilogía de las Marías, en particular en María la del Barrio, la protagonista es caracterizada como buena, noble, dulce, pobre pero honrada, mientras que la antagonista Soraya es "la mala" y por ende muestra cualidades de seductora, despiadada, calculadora entre otras características descalificadoras. Este patrón también se repite, de forma notable, en los formatos que actualmente compra la televisión mexicana a industrias colombianas y argentinas. Por otro lado, las series de género dramático y suspenso, como es el caso de Mujeres Asesinas, serie basada en la trilogía de libros de la argentina Marisa Grinstein adaptada para México, también puso su cuota melodramática, al representar a las mujeres que asesinaban como víctimas de sus propias confusiones, matando por decepción, venganza, resentimiento, por sentirse engañadas o humilladas.

En cuanto a las telenovelas de Brasil, Mazziotti las describe de la siguiente manera:

Es un modelo permisivo en el plano moral. No hay condena explícita a la sexualidad, se permiten parejas en las que la mujer es mayor, o en las que la madre sea amante de quien después será su yerno.... La temática melodramática se mantiene, pero sin la cuota de sufrimiento expresado de manera exagerada... Los personajes crecen, maduran, cambian, evolucionan, eligen, involucionan. Dialogan y debaten entre sí, tienen puntos de vista diferentes, divergentes. (Mazziotti, 2008)

Esta descripción dista mucho del ejemplo anterior pues los personajes gozan de una libertad mucho más cercana a la realidad. No se encasillan dentro de una manera de actuar, sino que reflejan lo aleatorio y hasta cierto punto contradictorio de la naturaleza humana. El sufrimiento no se ve como una condición necesaria para alcanzar una meta, sino que es un elemento que puede aparecer o no.

Por último, en las telenovelas provenientes de Colombia se evidencia una representación 
descentralizada desde el punto de vista geográfico; esto trae como consecuencia la combinación de dos o más mundos, lo moderno y lo tradicional; de esta forma, la telenovela colombiana a comparación, por ejemplo, de la mexicana, parece retar los estereotipos enraizados en su sociedad. Según Mazziotti, esto se da en Betty la Fea, que no se llega a hacer cirugías sino que encuentra la seguridad en su interior, como también la telenovela Todos quieren con Marilyn, en la que una prostituta que es buena y aconseja a sus amigas que no sigan por ese camino, finalmente revierte su historia.

De los tres modelos, diría que el de Televisa aparece seguro en lo que está. El modelo Globo innova y experimenta, pero dentro de una búsqueda estética que se aleja cada vez más de la emoción. Tal vez parece demasiado frío, cerebral. El modelo colombiano es el que se presenta más abierto. Es una narrativa en búsqueda, en exploración de nuevos caminos. (Mazziotti, 2008)

Es justamente a la exploración a la que Mazziotti hace referencia la que incentivo el artículo en curso. Desde la recordada Café con Aroma de Mujer, las telenovelas colombianas nos avisaban de su interesante aporte para el trabajo de representación, el cual se consolidó aun mas al empezar a exportar sus productos en formatos llenos de temas que empezarían a cuestionar al televidente y que este empieza a aceptar sin tanto esfuerzo, mas bien con una actitud quizá mas reflexiva. Por tal motivo, analizaré el modelo de telenovelas en Colombia, para ser más exacta, el de la telenovela El último matrimonio feliz (en adelante EUMF).

\section{EL CASO COLOMBIANO: EL ÚLTIMO MATRIMONIO FELIZ}

Antes de empezar a analizar la representación de las mujeres colombianas en EUMF, es importante conocer el origen de la idea detrás de esta telenovela. En una entrevista de marzo del 2009 con el diario colombiano El Tiempo, la libretista graduada de comunicación social y periodismo de la Pontificia Universidad Javeriana Mariana Suarez relata cómo su separación matrimonial la llevó a interrogarse por qué los matrimonios se estaban acabando. Ella se basó en estudios sobre el maltrato hacia las mujeres en Latinoamérica, junto con la orientación de expertos en la materia, sociólogos, escritores y psicólogos. Fue entonces que tuvo información rica en contenido para narrar una historia.

Esta introducción ya podría darnos una idea de que EUMF no solo es un estudio interesante de representatividad, sino también el análisis de resultados llevados a la pantalla. La producción, realizada en 2009 , consta de 120 capítulos que narran la difícil situación de seis matrimonios y el cuestionamiento de seis mujeres: Antonia, Bárbara, Paulina, Camila, Margot y Yorlei, frente a su relación conyugal. $\mathrm{He}$ decidido analizar la representación de estas mujeres en referencia a la problemática que describen sus personajes. Adicionalmente, considero la representación de la historia de Angela por considerarse interesante en la discusión. Para este propósito, he decidido dividir los temas en base a los votos que se realizan en los matrimonios y encontrar el vínculo contradictorio entre estos y las historias narradas.

\section{En la salud y en la enfermedad}

La primera historia, de Antonia, es la de una mujer profesionalmente exitosa y con una familia amorosa. Sin embargo, la exigencia de su jefe y los retos laborales inherentes a su condición femenina la obligan a priorizar su trabajo. A pesar del apoyo de su esposo e hija, ellos sienten que el trabajo les impide disfrutar de tiempo como familia. Lo peor no sucederá sino hasta que a ella se le diagnostica cáncer de seno. Es quizá aquí donde su historia explica el interés del presente trabajo. Por un lado, la representación refleja el temor a afrontar una enfermedad que sobre todo estos últimos años ha sido conocida, pero que muchas mujeres preferirían ignorar. Por otro lado, es importante analizar las consecuencias que la extirpación de un seno pueda traer a una relación conyugal y su intimidad. En este caso, la fragilidad de una persona ante un mal severo es puesta en 
evidencia, lo que podría ayudar a la mujer a tomar consciencia de que su bienestar físico es tan importante como su desarrollo profesional.

La segunda historia, de Bárbara, es la de una esposa con una baja autoestima oculta en una actitud alegre y optimista, pero que permite que su esposo, que abusa del alcohol y demuestra celos, la maltrate física y verbalmente. A pesar de los maltratos que Bárbara recibe, ella se encuentra en negación y piensa que la reacción de su esposo es pasajera. Esta historia demuestra que una víctima no necesariamente se muestra como tal o como una heroína; es probable que muchas mujeres también hayan atravesado situaciones en las que atribuían un comportamiento violento del esposo a una situación transitoria y por ello poco importante, y el desarrollo de la historia mostrará lo dañino de esta actitud en la autoestima.

\section{En la riqueza y en la pobreza}

La tercera historia, de Paulina, es la de una mujer orgullosa que no concibe la idea de que su esposo es exitoso profesionalmente, pese a que ella también lo es. Su relación termina y su esposo inicia los trámites de divorcio. Durante ese proceso, como Paulina sabe que no puede estropear la vida profesional de su esposo, decide no darle el divorcio incluso sabiendo que él se ha vuelto a enamorar y hace todo lo posible por tomar revancha. Aquí se cuestiona el éxito, cómo lo obtenemos y con quién lo compartimos: en la actualidad, la mujer ha ganado posiciones en el mercado laboral y su competitividad ha sido más que demostrada. Sin embargo, la manera como la telenovela representa esta situación cuestiona en qué medida el triunfo o el éxito profesional podrían constituir nuestra plenitud, o a qué punto se podría llegar para obtenerlos, inclusive sacrificando la vida conyugal.

La cuarta historia, de Camila, es la de una mujer de vida oscura que contrae matrimonio con un hombre exitoso que la inserta en la sociedad colombiana creándole una persona totalmente falsa. Su vida fluctúa entre las vejaciones de parte de su esposo y su imposibilidad de separarse de él por su falta de identidad y la incertidumbre de un futuro sin las comodidades a las que se ha acostumbrado. En este caso, la telenovela plantea un tema sensible: cómo una mujer afronta o deja de afrontar una relación infeliz únicamente debido a su temor de encontrarse en un vacío existencial probablemente motivado por una dependencia material o espiritual de su pareja.

\section{En lo próspero y en lo adverso}

La quinta historia es la de Margot, una mujer de aproximadamente 50 años con dos hijos adolescentes y un esposo que le es constantemente infiel. Ella se esfuerza por consentir a su familia y para eso no solo trabaja en su casa sino también como secretaria, nunca descansa, y el estrés hace que descuide su alimentación, lo que le genera sobrepeso. Es tan poco tiempo el que tiene para ella que nunca se ha cuestionado si vive feliz como lo hace o si su pareja la hace feliz, pues el trato que recibe por parte de él es tan superficial, que aparentemente ella ya lo naturalizó. Cuando finalmente se da cuenta que su esposo la ha reemplazado por una mujer más joven, ella intenta someterse a tratamientos de belleza como la liposucción para retener al padre de sus hijos. Esta representación cuestiona frontalmente los estándares de belleza del mundo actual y cuánto podría hacer alguien por retener a su pareja, sin considerar los riesgos para su salud física y emocional.

\section{Hasta que la muerte los separe}

La sexta historia es la de Yorlei, una mujer trabajadora que mantiene económica $y$ moralmente a su hija y a su esposo, pues este último no desea aceptar trabajos que no estén a su nivel académico. La relación no solo se torna difícil con su pareja, sino también con su niña que la rechaza pues considera que su mamá no quiere a su papá y lo humilla por no aportar dinero al hogar. Este rechazo se intensifica más cuando la hija de Yorlei se entera que un buen hombre se ha enamorado de su madre. El tema que esta historia propone es quizá muchas veces visto, pero pocas veces discutido y es interesante como esta representación interpela a la sociedad y su juzgar para con las mujeres, que después de una separación, reconsideran construir su vida sentimental. Más difícil pueda 
resultar la situación si hay hijos de por medio. Contrastándolo con la realidad, es muy común el relato de las mujeres que deciden quedarse al lado de sus esposos por el bienestar de sus hijos y este ejemplo claramente interpela en qué medida esto se convierte en una solución $y$ no en un problema a largo plazo.

Por finalizar, el desenlace que narra el último capítulo de la historia de Ángela y Alcides, es un ejemplo interesante de análisis. Durante los 120 capítulos Ángela ha estado inmensamente enamorada de Alcides, quién se sabe es homosexual pero no lo admite abiertamente. El jefe de Ángela, quien ha tenido una relación con Alcides, intenta convencerla de no aceptar la propuesta de casarse con su expareja. Sin embargo, Alcides llega a la iglesia y Ángela, sabiendo que se está a punto de casarse con una persona que no solo no la ama, sino también que es homosexual, decide contraer matrimonio. Es interesante el dialogo previo que Ángela tiene con su madre, pues allí acepta que podría resistir todo menos quedarse soltera. Nuevamente, cuan interesante es este relato para reflexionar acerca del peso de la sociedad sobre las personas que deciden quedarse solteras y cuales son los límites en estas situaciones.

Lo interesante de estas historias fue que ninguna tuvo un final drástico. Si bien es cierto todas terminan con una sonrisa, este final no copia el 'y vivieron felices para siempre', pues cada una aún tiene muchas cosas que resolver en su vida, nuevas aspiraciones pero también recuerdos nostálgicos que les resuenan que la vida es difícil de definir.

Las historias no solo tuvieron repercusión en la gran aceptación traducida en una gran aceptación de los televidentes o en reconocimientos de la industria televisiva, sino también en campañas sociales como la Lucha contra el cáncer y la del Ministerio de Protección Social de Colombia, que junto con los personajes de la historia, emprendieron un debate social sobre el maltrato físico y emocional (El Tiempo, 2009).

Considero importante la reflexión del trabajo de representación que se realizo en esta novela, no solo por haber puesto en el tapete las razones por las que mas parejas deciden divorciarse y las causas que los llevaron a tal, sino también la narración de las historias de estas seis mujeres que de manera diversa desafían los estereotipos comúnmente 'naturalizados'. En tal sentido, creo propicio el comentario optimista del Dr. Barbero en referencia a la representación de la mujer en los medios de la sociedad colombiana.

Las imágenes de la mujer en los medios audiovisuales -que son a los que mayor acceso tiene la gente del común, y los que mayor influencia ejercen sobre su sentido de la vida- han sido históricamente de dos tipos: unas han venido sosteniendo la concepción patriarcal y machista sobre la mujer, pero también ha habido, y hay hoy, imágenes que han contribuido a su emancipación. Yno solo en el cine, también las series argumentales y dramatizadas de televisión han mostrado en nuestros países cómo fueron cambiando las costumbres en otros países: la legitimidad del divorcio, la necesidad del control de natalidad, las transformaciones de la familia, las formas femeninas de la liberación sensorial. (Barbero, 2007)

\section{CONCLUSIONES}

El género telenovela ha contribuido significativamente a la representación de la mujer en los medios de comunicación a través de retratos diversos. Por ende, la construcción de la identidad femenina se debe en gran parte a este fenómeno cultural.

Las características de los personajes de las telenovelas muestran en mayor o menor grado cómo se manifiesta un grupo social determinado. En el caso de El último matrimonio feliz, las historias de las mujeres son más cercanas a la realidad que las de otras producciones televisivas, debido a que la complejidad de su situación $y$ los conflictos que desean o no enfrentar reflejan un desafío para el público, ya que este observará una realidad con matices y no estereotipada. 
Sería interesante comparar este tipo de representaciones y su trasfondo con el caso peruano. Sin embargo, en los últimos años el género telenovela ha tenido un retroceso frente a los programas reality, que ahora brindan la cuota de melodrama anteriormente presente en las telenovelas.

\section{REFERENCIAS}

Barker, Chris. (1999) Television, Globalization and Cultural Studies. United Kingdom. Open University Press.

Barbero, J. (1987) De los Medios a las Mediaciones. Barcelona: Gustavo Gili.

Barbero, J. (2007) Conferencia Medios de comunicación y violencia contra la mujer. Bogotá: Consejería Presidencial para la Equidad y la Mujer. Disponible en Internet http://www.mediaciones. net/2007/01/medios-de-comunicacion-y-violencia-contra-la-mujer/

Bateman, A., Casey, S., Mortimer, C., Wall, P. (2011) Media Studies. Oxon: Routledge.

Casey, B. (2008) Television Studies, The Key Concept. Oxon: Routledge.

Evans, J., Hall, S. (eds) (1999) Visual Culture. London: SAGE.

Fiske, J. y Hartley, J. (1978) Reading television. London and New York: Routledge.

Fiske, J. (1987) Television Culture. London: Routledge.

Geraghty, C. y Lusted, D. (1998) The Television Studies Book. London: ARNOLD.

Helsby, W. (ed). (2005) Understanding Representation. London: British Film Institute.

Hall, Stuart. (1981) Encoding, Decoding in S. Hall, D. Hobson, A. Lowe and P. Willis (eds) Culture, Media, Language. London: Hutchinson.

Hall, Stuart. (1996) New Ethnicities in D. Morley and D-K. Chen (eds) Stuart Hall. London: Routledge.

Hall, Stuart. (ed). (1997) Representation: Cultural Representations and Signifiying Practices. London: The Open University.

Lauzen, M. (2013) The Celluloid Ceiling: Behind - the - scenes employment of women in the top 250 films of 2012. San Diego: Center for the Study of Women in Television and Film, School of Theatre, Television and Film, San Diego State University. Disponible en Internet http:// womenintvfilm.sdsu.edu/files/2012_Celluloid_Ceiling_Exec_Summ.pdf. 
Lauzen, M. (2012) Boxed in: Employment of behind-the-scenes and on-screen women in the 2011-12 prime-time television season. San Diego: Center for the Study of Women in Television and Film, School of Theatre, Television and Film, San Diego State University. Disponible en Internet http://womenintvfilm.sdsu.edu/research.html.

Marris, P. y Thorham, S. (ed). (1996) Media Studies. A Reader. Edinburgh: Edinburgh University Press.

Mazzioti, N. (2008) La telenovela y su hegemonía en Latinoamérica. Lima: Revista digital $\mathrm{N}^{\circ} 1$ - La Mirada de Télemo- del Departamento Académico de Comunicaciones de la Pontificia Universidad Católica del Perú. Disponible en Internet http://revistas.pucp.edu.pe/index.php/lamiradadetelemo/ article/view/3485/3381.

Proyecto de Monitoreo Global de Medios. (2010) ¿Quién figura en las noticias?. Informe del Proyecto de Monitoreo Global de Medios. Londres: Asociación Mundial para la Comunicación Cristiana (WACC).

Siebel, J. (2011) Miss Representation. DVD.

Suarez, A. (2008) Telenovela El Último Matrimonio Feliz. Bogotá: RCN Televisión.

Velasco, A. (2009) Adriana Suarez, la libretista de "El último matrimonio feliz". Periódico El Tiempo. Sección Gente. Disponible en Internet http://www.eltiempo.com/archivo/documento/ CMS-4882743 